\title{
Lactose Crystallization Delay in Model Infant Foods Made With Lactose, $\beta$-Lactoglobulin, and Starch
}

\author{
A. Nasirpour, ${ }^{\star 1}$ V. Landillon,† B. Cuq, $†$ J. Scher, ${ }^{*}$ S. Banon, ${ }^{*}$ and S. Desobry* \\ *Nancy-Université, ENSAIA-INPL, Laboratoire de Science et Génie Alimentaires, 2 av. de la Forêt de Haye, \\ F-54505 Vandoeuvre lés Nancy, France \\ †UMR1208 Ingénierie des Agropolymères et Technologies Emergentes, AgroM, CIRAD, INRA, Université Montpellier 2, \\ 2 place Viala, F-34000 Montpellier, France
}

\begin{abstract}
Handling and storage alter infant food powders due to lactose crystallization and interactions among components. Model infant foods were prepared by colyophilization of lactose, $\beta$-lactoglobulin ( $\beta$-LG), and gelatinized starch. A mixture design was used to define the percentage of each mixture component to simulate a wide range of infant food powders. The kinetics of crystallization was studied by a gravimetric method (dynamic vapor sorption) at $70 \%$ relative humidity (RH). After freezedrying, lactose was amorphous and crystallized at 70\% $\mathrm{RH}$. The delay before crystallization depends on the contents of $\beta$-LG and starch in the formulations. A mathematical model was proposed to predict crystallization time (delay) at 70\% RH. For the formulation containing $50 \%$ lactose, $25 \% \beta$-LG, and $25 \%$ starch, lactose was still amorphous after $42 \mathrm{~h}$ at $70 \% \mathrm{RH}$, whereas pure amorphous lactose crystallized after approximately 70 min. Calculated and experimental results of adsorbed moisture from the formulations were compared. Adsorbed water of formulation containing lactose could not be calculated from moisture sorption properties of each component at a given $\mathrm{RH}$ because $\beta$-LG and gelatinized starch prevented lactose crystal growth.
\end{abstract}

Key words: kinetics of crystallization, moisture sorption, amorphous lactose

\section{INTRODUCTION}

Infant formulation contains a large quantity of lactose, present in both the amorphous and crystallized states. Amorphous lactose is meta-stable and may be softened or plasticized by temperature and water. Lactose crystallization causes the most drastic changes during storage of powder containing lactose. The most important changes that occur are water liberation (Thomas et al.,

Received March 7, 2007.

Accepted April 18, 2007.

${ }^{1}$ Corresponding author: ali.nasirpour@ensaia.inpl-nancy.fr
2004; Nasirpour et al., 2006), stickiness, caking, collapse (Lloyd et al., 1996; Rennie et al., 1999; Özkan et al., 2003), and acceleration of nonenzymatic browning (Karmas and Karel, 1994). Lactose crystallization in milk powders leads to increased free fat and flavor deterioration and may promote nonenzymatic browning (Kim et al., 1981). Crystallization could be delayed by incorporation of high molecular weight substances such as proteins (Levine and Slade, 1986; Nasirpour et al., 2006) or sugars other than lactose (Herrington and Brandfield, 1984). Many factors affect lactose crystallization such as temperature, relative humidity (RH; Vuataz, 2002), storage time, and mixture composition (e.g., proteins in milk powder or infant foods). Lactose crystallization can be predicted from the state diagram of lactose. Nevertheless, the state diagram is static, and time is not taken into consideration. It is important to consider time as an important parameter for predicting the state changes of lactose under different storage conditions. An exact determination of crystallization time or delay before crystallization depends on the frequency of analyzed samples especially with the desiccator method. Any thermal or RH change during analysis of samples affects lactose crystallization. Dynamic vapor sorption (DVS) measures mass changes of samples over time at a given $\mathrm{RH}$ and temperature. The delay before crystallization could be measured when water liberation occurs at given $\mathrm{RH}$ and temperature values.

In this study, kinetics of lactose crystallization and delay before crystallization were studied by DVS in model infant foods containing lactose, $\beta$-LG, and gelatinized starch. Effects of $\beta$-LG and starch on kinetics of lactose crystallization were studied using an experimental design. Furthermore, moisture sorption properties of model formulations were compared using calculated moisture sorption data.

\section{MATERIALS AND METHODS}

\section{Model Infant Formulation Preparation}

Model formulations were prepared by mixing 3 major components of infant formulations (lactose, $\beta-\mathrm{LG}$, and 
starch) as previously described by Nasirpour et al. (2006). Gelatinized wheat starch suspensions (Sigma Chemical Co., St. Louis, MO) were produced using a 5\% (wt/wt) solid suspension. The suspensions were heated to boiling under continuous stirring to obtain gelatinized starch. After cooling, this solution was mixed with $\beta$-LG (Davisco, Eden Prairie, MN) solution (10\%) and lactose (Prolabo, Fontenay-sous-Bois, France) solution (15\%) at different ratios to obtain the model formulations. After 30 min of mixing, $70 \mathrm{~mL}$ of the final mixture was placed into 500-mL round-bottomed flasks and was frozen at $-40^{\circ} \mathrm{C}$ for $45 \mathrm{~min}$ in a refrigerated bath (Polystat cc241, Offenburg, Germany). The samples then were freezedried (Christ Alpha 1-2, Christ Gefriertrocknungsanlagen $\mathrm{GmbH}$, Osterode am Harz, Germany) for $48 \mathrm{~h}$ at $-60^{\circ} \mathrm{C}$ and $10 \mathrm{~Pa}$ to obtain amorphous lactose. Water content of all samples was measured after freeze-drying and samples had less than $2 \%$ water (dry basis). The samples were stored for 2 wk over $\mathrm{P}_{2} \mathrm{O}_{5}$ to complete the drying process. Three samples of each formula were kept on $\mathrm{P}_{2} \mathrm{O}_{5}$ for 3 mo to determine the initial water content of samples.

Colyophilized formulations (F) contained 3 components and were designated as lactose/starch/ $\beta$-LG (wt/ wt), such that F80/10/10 indicates a formulation containing $80 \%$ lactose, $10 \%$ gelatinized starch, and $10 \% \beta$ LG (wt/wt).

\section{Kinetics of Lactose Crystallization by DVS}

Kinetics of water adsorption was determined at $20^{\circ} \mathrm{C}$ by using a controlled atmosphere microbalance (DVS apparatus, Surface Measurement System Ltd., London, UK). The apparatus consisted of a Cahn (Thermo Fisher, Waltham, MA) microbalance housed in a controlled temperature incubator $\left( \pm 0.1^{\circ} \mathrm{C}\right)$. The required humidity levels were generated by mixing dry and saturated vapor gas flows in the correct proportions using flow controllers (model 1179A, Mass-flo and meter controller, MKS Instruments, Cheshire, UK). Humidity and temperature probes situated just below the sample and reference holders gave independent verification of system performance. The microbalance was equipped with an electrobalance (model D-200, Cahn) for mass determination and a Rotronic (Rotronic Systems Ltd., Farnham, UK) humidity sensor for RH measurement. Samples (10 to $20 \mathrm{mg}$ ) were loaded and preequilibrated at $0 \% \mathrm{RH}$ $( \pm 0.4 \%)$ in a continuous flow of dry air. Preequilibration conditions were defined automatically when the change in sample mass as a function of time was lower than $0.002 \% / \mathrm{min}$ (i.e., $2.8 \mathrm{~g}$ of water/100 g dry basis per d).

Relative humidity was then increased to $70 \%$ for 15 to $100 \mathrm{~h}$ (to allow crystallization) depending on the lactose quantity in formulations. Mass changes (m) and the rate
Table 1. Initial experimental area for formulations

\begin{tabular}{lcc}
\hline & \multicolumn{2}{c}{ Content $(\%, w t / w t)$} \\
\cline { 2 - 3 } Component & Minimum & Maximum \\
\hline Lactose & 50 & 80 \\
Starch & 10 & 25 \\
$\beta$-LG & 10 & 25 \\
\hline
\end{tabular}

of mass changes $(\mathrm{dm} / \mathrm{dt})$ were plotted against time to compare lactose crystallization delay in the formulations.

\section{Scanning Electron Microscopy}

The samples were mounted on double-sided adhesive carbon tabs and were coated with gold using a metal sprayer (auto sputter coater E-5200, Bio-Rad, Polaron Equipment Ltd., Watford, UK) and were examined with a scanning electron microscope (Hitachi S2500, Hitachi, Tokyo, Japan).

\section{Statistical Analysis}

A mixture design based upon a 3-component mixture was used to explore the results in terms of moisture sorption. The experimental domain (Table 1) was chosen according to the European Standards for infant formulation (Food Safety Authority of Ireland, 2001). Mixture design is an efficient method to study the effect of several parameters distinguishing between process variables (e.g., temperature, $\mathrm{RH}, \mathrm{pH}$ ) and mixture factors such as a formulation's components (Cafaggi et al., 2003). When working with 3 components, the experimental domain corresponds to a triangle. All possible mixtures could be identified by a point in this space with vertices corresponding to the pure components. The experimental results were analyzed using Expert Design 6.0.6 trial (Stat-Ease Inc., Minneapolis, MN). The ANOVA was performed to determine the statistical significance of the fitted models.

\section{RESULTS AND DISCUSSION}

\section{Kinetics of Crystallization at $70 \% \mathbf{R H}$}

After 2 wk of storage of samples under $\mathrm{P}_{2} \mathrm{O}_{5}$, crystallization kinetics were measured by placing the samples at $70 \% \mathrm{RH}$. Figure 1 shows adsorbed water of samples vs. time for pure lactose and formulations F50/25/25, F80/10/10, F 72.5/10/17.5, F65/21.25/13.75, and F57.5/ 25/17.5. All formulations except pure lactose adsorbed approximately the same quantity of water (15 to 18\%) before crystallization. Pure lactose adsorbed only $7.6 \%$ (wt/wt) water before crystallization. A sharp drop in ad- 


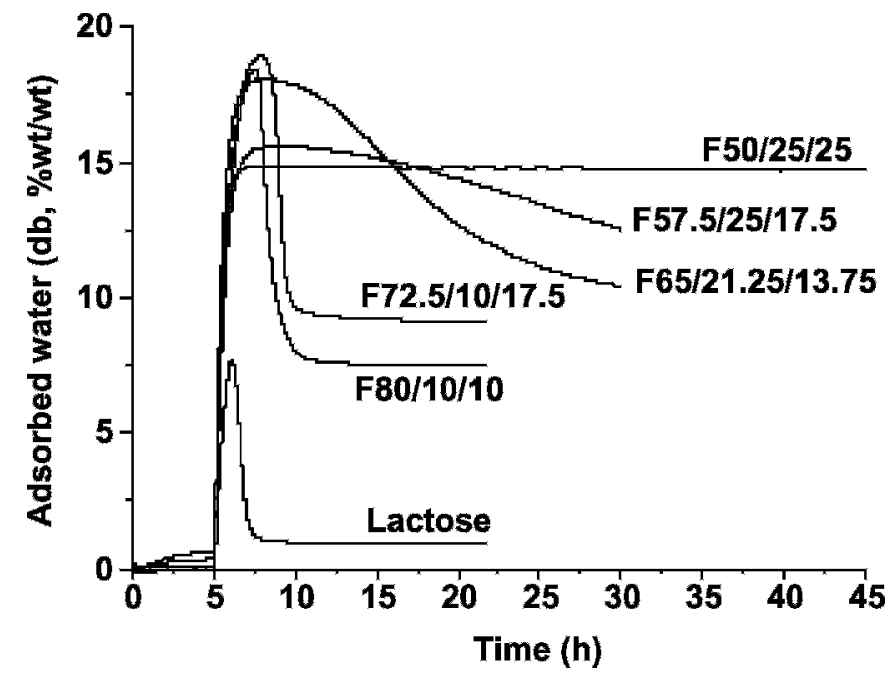

Figure 1. Moisture sorption of several formulations (F) based on F50/25/25 (content of lactose/starch/ $\beta$-LG, \% wt/wt), F80/10/10, F $72.5 / 10 / 17.5$, F65/21.25/13.75, F57.5/25/17.5, and pure lactose at 70\% relative humidity and $20^{\circ} \mathrm{C}$; $\mathrm{db}=$ dry basis.

sorbed water (Figure 1) shows water liberation by samples. Crystallization phenomena occur in 2 steps: nucleation and growth of these nuclei, with water being liberated during crystallization. The quantity of water liberated during crystallization depends on many parameters including lactose crystal shape, size, and arrangement.

Crystallization of pure lactose was more rapid compared with that of other formulations. However, when the crystallization phenomenon is rapid, the different steps of crystallization occur simultaneously. Water liberation occurred concurrently with nucleation and crystal growth. This is why maximum water adsorbed before crystallization in the case of pure lactose was less than in the other formulations. Pure lactose only adsorbed about $1.8 \%$ water after crystallization, indicating that crystallized lactose is not hygroscopic.

As shown in a previous study (Nasirpour et al., 2006), starch and $\beta$-LG adsorb a large quantity of water at high $\mathrm{RH}$ compared with lactose. By increasing the $\beta$-LG and starch quantity in formulations, adsorbed water increased. Formulation F80/10/10 adsorbed approximately $18.3 \%$ water at $70 \% \mathrm{RH}$ before crystallization and liberated a large quantity of water, as was the case for F72.5/ $10 / 17.5$. After equilibrium (when $\mathrm{dm} / \mathrm{dt} \approx 0$ ), as expected, the formulation containing $50 \%$ lactose adsorbed more water $(14.7 \%)$ than did other formulations.

For formulation F50/25/25, water liberation (drop in the moisture sorption curve) was not observed, because this formulation was not crystallized at $70 \% \mathrm{RH}$ after $42 \mathrm{~h}$. However, by increasing the $\mathrm{RH}$ to $80 \%$, water liber-

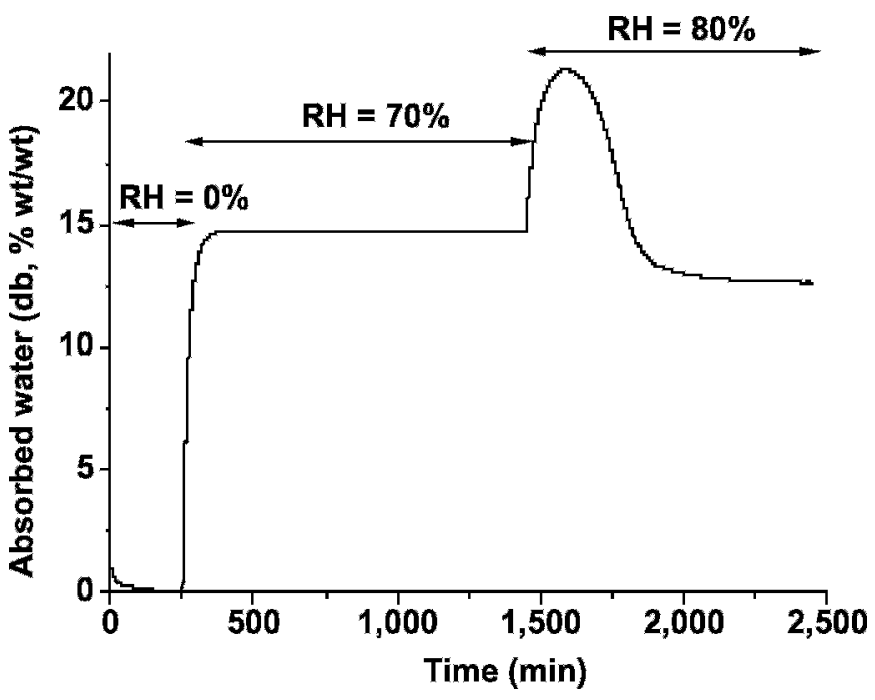

Figure 2. Moisture sorption of formulation F50/25/25 (50\% lactose, $25 \%$ gelatinized starch, and $25 \% \beta$-LG) at $80 \%$ relative humidity $(\mathrm{RH})$ and $20^{\circ} \mathrm{C} ; \mathrm{db}=$ dry basis.

ation was observed after about 3 h 40 min (Figure 2). Formulations F80/10/10, F72.5/10/17.5, and F65/21.25/ 13.75 adsorbed more water than F50/25/25 before crystallization. Water liberation can be observed for these formulations (Figure 1); after crystallization, they adsorbed less water than did F50/25/25. As several authors have shown, moisture sorption properties of formulations depend on the moisture sorption properties of each component (Labuza et al., 1970; Thomas et al., 2004).

For any mixture at equilibrium, the water activity $\left(\mathbf{a}_{\mathbf{w}}\right)$ of all components is equal. If only water is transferred between components during the process of equilibrium, each component will assume an equilibrium moisture content at a given $a_{w}$ equal to what can be obtained from its individual sorption isotherm. Expressing the equilibrium moisture content on a dry basis, the composite equilibrium moisture content for the mixture can be calculated from the weighted-average hypothesis using the equation

$$
\mathrm{M}_{\mathrm{cal}}=\frac{\Sigma \mathrm{W}_{\mathrm{i}} \mathrm{M}_{\mathrm{i}}}{\Sigma \mathrm{W}_{\mathrm{i}}}
$$

where $\mathrm{M}_{\text {cal }}$ is the calculated total moisture content at a specific $\mathrm{a}_{\mathrm{w}}, \mathrm{W}_{\mathrm{i}}$ is the individual component weight expressed on a dry basis, and $\mathrm{M}_{\mathrm{i}}$ is moisture content of the individual component. Lactose, $\beta$-LG, and starch adsorbed about 1.8, 16.85, and $15.27 \%(\mathrm{wt} / \mathrm{wt})$ at $70 \% \mathrm{RH}$, respectively. By considering these values, adsorbed water quantity can be calculated for all formulations. For example, in the case of F50/25/25, the calculated value of adsorbed water is around $8.4 \%$ (wt/wt), and a large 
Table 2. Comparison between calculated and experimental data for adsorbed moisture $(\%, \mathrm{wt} / \mathrm{wt})$ at $70 \%$ relative humidity $(\mathrm{RH})$ measured by dynamic vapor sorption method

\begin{tabular}{lcc}
\hline Formulation $^{1}$ & $\begin{array}{c}\text { Calculated }^{2} \\
(\mathrm{~g} / 100 \mathrm{~g} \text {, dry basis })\end{array}$ & $\begin{array}{c}\text { Experimental } \\
(\mathrm{g} / 100 \mathrm{~g}, \text { dry basis })\end{array}$ \\
\hline F80/10/10 & 4.60 & 7.35 \\
F72.5/10/17.5 & 5.73 & 9.14 \\
F72.5/13.75/13.75 & 5.67 & 8.25 \\
F72.5/17.5/10 & 5.61 & 7.70 \\
F65/10/25 & 5.69 & 9.01 \\
F65/13.75/21.25 & 6.80 & 10.48 \\
F65/17.5/17.5 & 6.99 & 8.96 \\
F65/21.25/13.75 & 6.69 & 8.00 \\
F65/25/10 & 6.63 & 8.78 \\
F57.5/25/17.5 & 8.40 & 12.36 \\
F50/25/25 & 8.90 & 14.70
\end{tabular}

${ }^{1}$ Formulations (F) indicate the content (\%, wt/wt) of lactose/starch/ $\beta$-LG.

${ }^{2}$ The calculated data were obtained from the moisture sorption of each component at $70 \% \mathrm{RH}$.

difference between calculated and experimental values (14.7\% wt/wt) was observed. Crystallization did not occur in this formulation, which explains the large difference between calculated and experimental results. Gelatinized starch and $\beta$-LG played an important role in crystallization time. Formulations containing a large quantity of $\beta$-LG or gelatinized starch crystallized later compared with pure lactose.

Table 2 shows the experimental and calculated values of adsorbed water of formulations at $70 \% \mathrm{RH}$. A difference between calculated and experimental results exists for all samples except F80/10/10. When formulations contained lactose, adsorbed water could not be calculated from sorption properties of individual components.

Bronlund and Paterson (2004) used a similar approach for predicting the isotherm of a crystalline lactose powder containing 9\% amorphous lactose. They predicted the measured isotherm accurately up to the breakpoint in the isotherm, which was due to amorphous lactose crystallization. It was suggested that this simple additive isotherm approach could be used for measuring the amorphous lactose content of lactose powders. On the other hand, we found that when formulations contain lactose, calculated and experimental results were different. The tightly packed molecules in pure lactose adsorb very little water, and then only on crystal surfaces. By adding gelatinized starch and $\beta$-LG, the shape and arrangement of lactose crystals changed. Thus, lactose in formulations adsorbed more water compared with pure lactose in the same condition. Therefore, the difference between calculated and experimental results was due to the larger surface area available for water adsorption for lactose colyophilized with gelatinized starch and $\beta$ LG compared with pure lactose. As the size of the lactose crystals increased, the surface area decreased; thus, lactose crystals adsorbed less water.

Figure 3 shows scanning electron micrographs of 5 formulations under $70 \% \mathrm{RH}$ at different storage times. The particle shapes of freeze-dried milk and whey are different compared with spray-dried milk powder or whey powder, in which the particles have spherical forms (Saltmarch and Labuza, 1980).

Lactose crystals are observed on the surface of all samples except F50/25/25 under the conditions described in Figure 3. The formulation F50/25/25 had a smooth surface, with rough and irregular edges. In this case, the particles looked like plates or sheets, and lactose crystals could not be observed on the surface of particles. Our results indicated that water liberation was not observed in this case (Figure 1).

In the case of F57.5/25/17.5, lactose crystals appeared on particle surfaces after $25 \mathrm{~h}$ of storage at $70 \% \mathrm{RH}$ and water liberation was observed (Figure 1) under these conditions. The lactose crystals in F57.5/25/17.5 were smaller than in other formulations (Figure 3). Moreover, lactose crystals were not packed together compared with the formulations containing more lactose. By increasing the lactose quantity in formulations, lactose crystals were larger and more compact; consequently, they liberated more water.

Formulations containing a large quantity of lactose (e.g., F80/10/10) had large crystals compared with formulations containing less lactose (e.g., F57.5/25/17.5). In addition, lactose crystals in F80/10/10 were more compact. Size, shape, and arrangement of lactose crystals are very important for moisture sorption properties of formulations. Results of microscopy described why the moisture sorption of formulations could not be calculated from moisture sorption properties of each component.

To show the effect of $\beta$-LG and gelatinized starch on delay before crystallization, the rate of mass change $(\mathrm{dm} /$ $\mathrm{dt}$ ) was plotted against time (Figure 4). The minimum values in Figure 4 show the maximum rate of water liberation during crystallization. The time at maximum rate was around 98 min for pure lactose and was increased by increasing $\beta$-LG and starch quantity in formulations. For example, for F80/10/10, the time at maximum rate was around $183 \mathrm{~min}$. Moreover, by increasing $\beta$-LG and starch to $50 \%$ (wt/wt) in formulations, water liberation was not observed until 2,500 $\min (\sim 42 \mathrm{~h})$ of storage at $70 \% \mathrm{RH}$.

Delay before crystallization depends on the storage $\mathrm{RH}$, temperature, formulation composition, and other parameters. Vuataz (1988) found that lactose in skim milk powder crystallized at $39 \% \mathrm{RH}$ and $25^{\circ} \mathrm{C}$ after 200 $h$ of storage.

Results of crystallization time were analyzed by mixture design and the results of ANOVA and contour plot 


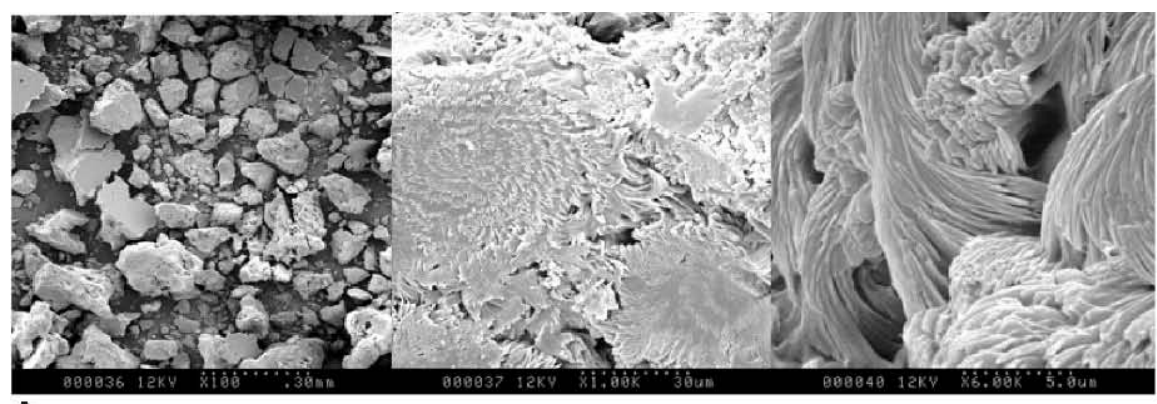

A

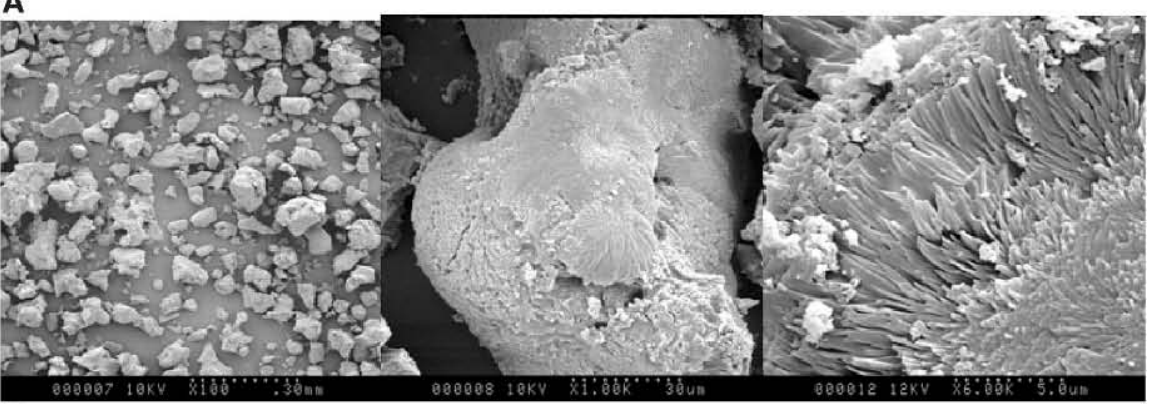

B

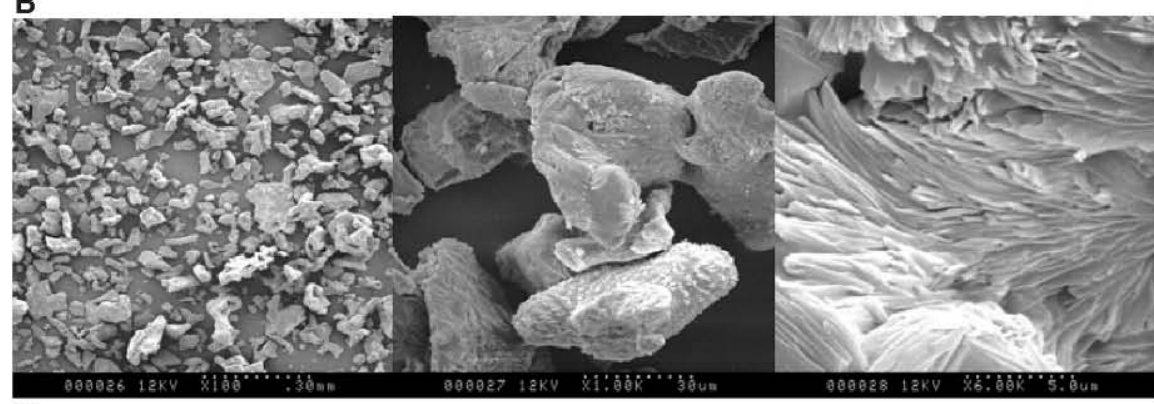

C

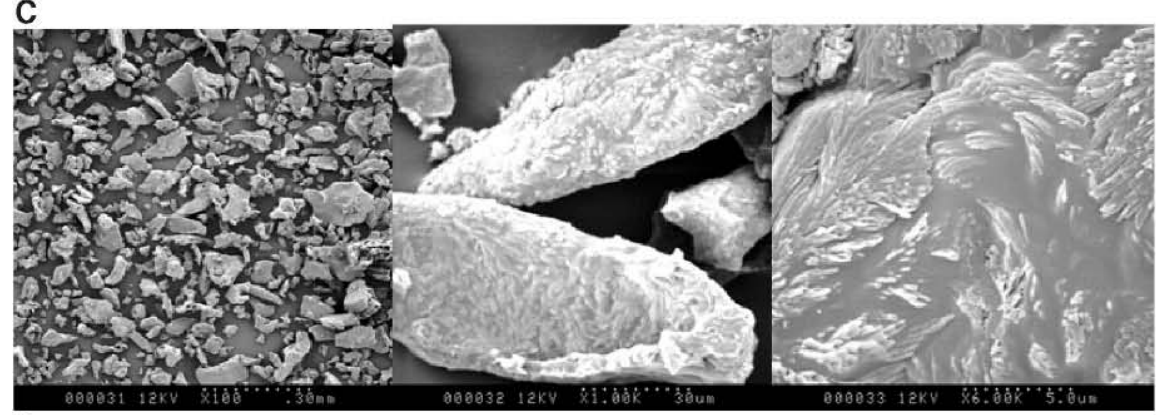

D

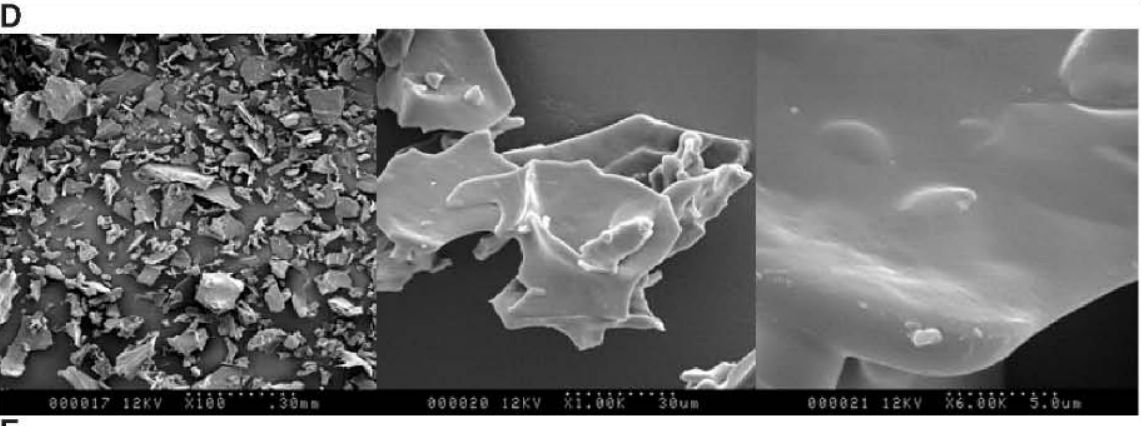

E

Figure 3. Scanning electron micrographs obtained from different formulations (content of lactose/starch/ $\beta$-LG, \% wt/wt): A) F80/10/10; B) F72.5/10/17.5; C) F65/21.25/13.75; D) F57.5/25/17.5; and E) F50/25/25. Formulations A, B, and C were stored at 70\% relative humidity $(\mathrm{RH})$ for 17, 17, and $25 \mathrm{~h}$, respectively; formulations $\mathrm{D}$ and $\mathrm{E}$ were stored at $70 \% \mathrm{RH}$ for 25 and $42 \mathrm{~h}$, respectively. 


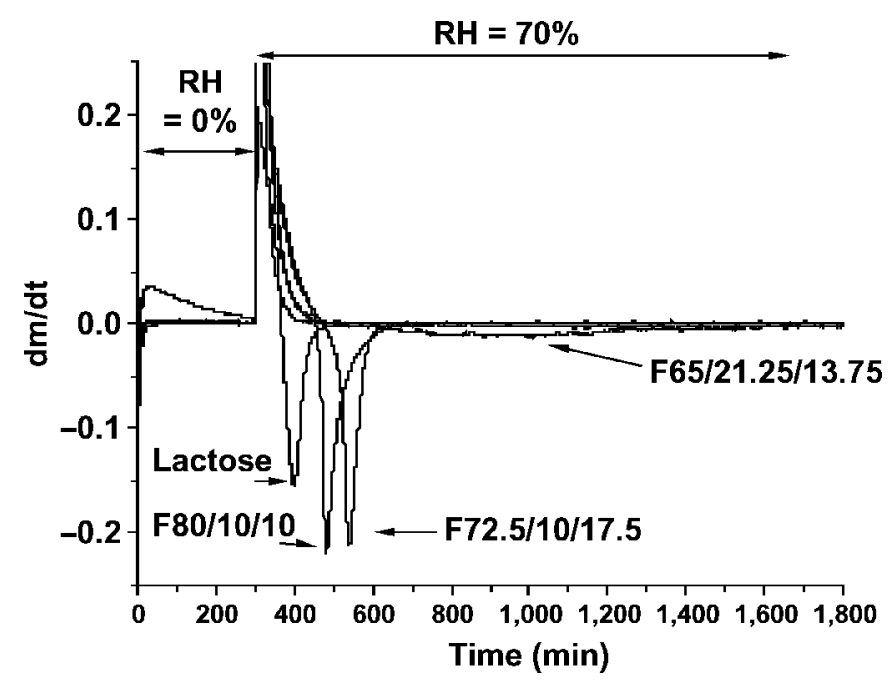

Figure 4. Rate of mass change $(\mathrm{dm} / \mathrm{dt})$ of lactose and 4 formulations (content of lactose/starch/ $\beta$-LG, $\%$ wt/wt) at $70 \%$ relative humidity $(\mathrm{RH})$. The minimum values show the maximum rate of water liberation during crystallization.

of predicted results are presented in Table 3 and Figure 5 . Interactions between lactose and starch and between lactose and $\beta$-LG had a significant effect on crystallization time, whereas interactions between starch and $\beta$ LG had no significant effect on crystallization time at $70 \% \mathrm{RH}$.

The coefficients of the quadratic model were estimated by the least squares method from the results given by the experiment and are presented in equation [2]. The statistical analysis and $R^{2}$ results $\left(R^{2}=0.99\right)$ showed that there was a strong agreement between calculated and experimental values:

$$
\begin{aligned}
& \text { Crystallization time }=2,105 \text { [lactose] }+26,577 \text { [starch] } \\
& +29,011[\beta \text {-LG] }-41,785 \text { [lactose] [starch] } \\
& -43,118 \text { [lactose] } \beta \text {-LG] }-26,132 \text { [starch] [ } \beta \text {-LG] }
\end{aligned}
$$

This model shows the importance of each component and the interactions between the components. Based

Table 3. Analysis of variance of crystallization time at $70 \%$ relative humidity

\begin{tabular}{lcrcl}
\hline Source & df & $F$-value & $P>F$ & \\
\hline Model (quadratic) & 5 & 194.44 & $<0.0001$ & Significant \\
Linear mixture & 2 & 463.53 & $<0.0001$ & Significant \\
Lactose and starch & 1 & 20.10 & $0.0029^{1}$ & Significant \\
Lactose and $\beta$-LG & 1 & 21.40 & $0.0024^{1}$ & Significant \\
Starch and $\beta$-LG & 1 & 3.62 & 0.0990 & Nonsignificant \\
\hline
\end{tabular}

${ }^{1}$ Values of $P>F$ less than 0.0500 indicate that model terms are significant.

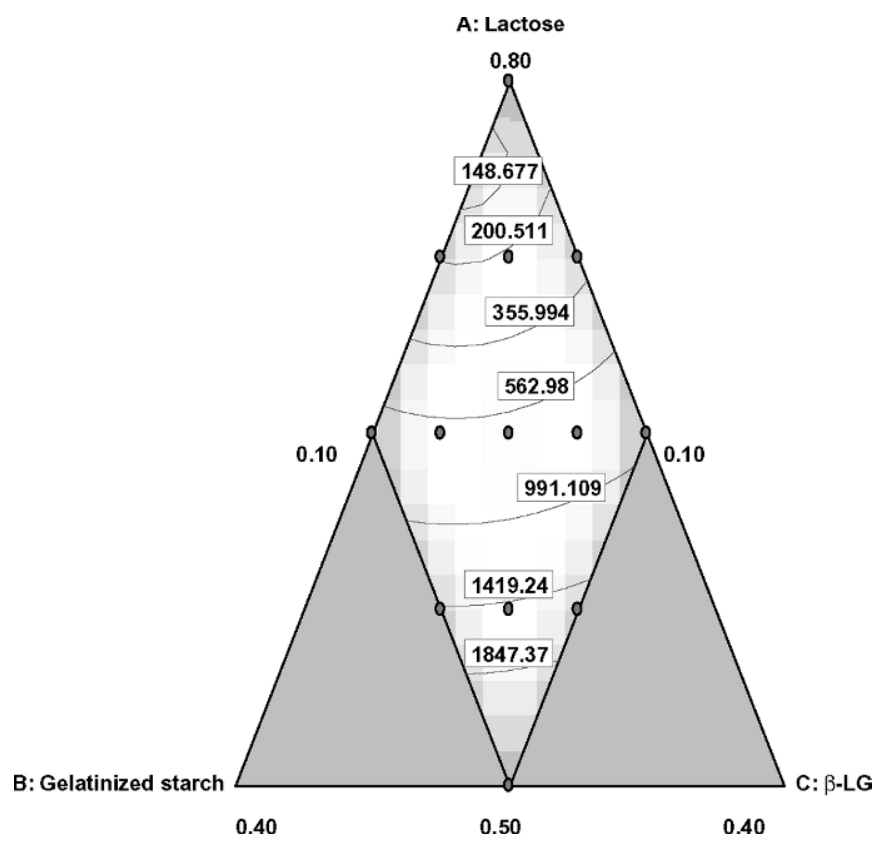

Figure 5. Contour plots of predicted response of crystallization time of formulations at $70 \%$ relative humidity and $20^{\circ} \mathrm{C}$.

on this equation, the influence of $\beta$-LG and gelatinized starch on crystallization time is more important than the component interactions. Interactions between components had a negative effect on crystallization time.

It is interesting to know the chemical composition of the particle surface. This could explain why moisture sorption properties of samples containing lactose above the $a_{w}$ value at which lactose crystallization occurs cannot be calculated from moisture sorption properties of each component (equation [1]). If all lactose present in the formulation is found on the surface of particles, then we would expect to have large crystals on the surface of particles. Several authors have studied the surface composition of powder containing proteins and saccharides by electron spectroscopy for chemical analysis (Fäldt and Bergenståhl, 1994; Millqvist-Fureby et al., 1999). Fäldt and Bergenståhl (1994) showed that protein appears on the surface of spray-dried mixtures of protein-lactose particles. Fäldt and Bergenståhl (1996) showed, by scanning electron microscopy, that lactose crystals appear on the surface of particles when crystallization occurs. An intact protein film was found on the surface of lactose crystals when analyzing the surface of particles. Gaiani et al. (2006) reported similar results for mixtures of spray-dried dairy powders containing high amounts of proteins.

The mechanism involved in freeze-drying is less clear, but it is possible that the adsorption mechanism is also valid for this process. The protein would adsorb on ice 
crystal surfaces in the frozen material before drying, which would be expected to result in an increase in the protein content on the surface of the freeze-dried powder compared with the bulk composition. Millqvist-Fureby et al. (1999) showed that proteins accumulated at the surface of freeze-dried protein-carbohydrate powders, and the mechanism of this adsorption is different compared with spray-drying method. The results of Millqvist-Fureby et al. (1999) showed that the protein composition of the particle surface increased until $80 \%$ of the protein is present on the particle surface. Therefore, this quantity of protein on the particle surface may prevent compaction of the lactose structure in the formulations, compared with pure lactose. Moreover, the presence of $\beta$-LG on the surface of particles explains why $\beta$-LG had a greater effect on lactose crystallization delay than gelatinized starch.

\section{CONCLUSIONS}

Dynamic vapor sorption is a rapid and efficient method to determine kinetics and moisture sorption properties of samples, especially in pharmaceutical and food studies. However, the time necessary for time-dependent phenomena (such as crystallization) to occur should be taken into consideration when using DVS. Moisture sorption kinetics of the samples depends on the composition and the interactions between the components. Water adsorption values were found to be higher in samples analyzed by DVS than in those calculated from the moisture sorption properties of each component. This is because $\beta$-LG and gelatinized starch affected lactose crystal size. By increasing $\beta$-LG and gelatinized starch quantities in formulations, lactose crystals were smaller. Lactose crystallization causes most of the drastic changes occurring in formula during storage such as caking and stickiness. Adding $\beta$-LG and starch increased the delay before lactose crystallization and increased the storage stability of infant formulas during storage. Delay before lactose crystallization depends on the many parameters including $\mathrm{RH}$, temperature, preferential exclusion, surface activity, steric hindrance of lactose-protein and lactosepolysaccharide interactions, and increased of viscosity of systems limiting structural movement. Delay before crystallization demonstrates that crystallization is a time-dependent phenomenon. By measuring this delay at other levels of $\mathrm{RH}$, it is possible to prepare a threedimensional state diagram for the formulation containing lactose.

\section{ACKNOWLEDGMENTS}

This work was supported by the Ministry of Science, Research and Technology and Isfahan University of Technology of Iran, which is gratefully acknowledged.

\section{REFERENCES}

Bronlund, J., and T. Paterson. 2004. Moisture sorption isotherms for crystalline, amorphous and predominantly crystalline lactose powders. Int. Dairy J. 14:247-254.

Cafaggi, S., R. Leardi, B. Parodi, G. Caviglioli, and G. Bignardi. 2003. An example of application of a mixture design with constraints to a pharmaceutical formulation. Chemometrics. Intell. Lab. Syst. 65:139-147.

Fäldt, P., and B. Bergenståhl. 1994. The surface composition of spraydried protein-lactose powders. Colloids Surf. 90:183-190.

Fäldt, P., and B. Bergenståhl. 1996. Spray-dried whey protein/lactose/ soybean oil emulsions. 1. Surface composition and particle structure. Food Hydrocoll. 10:421-429.

Food Safety Authority of Ireland (FSAI). 2001. Guidance note on the implementation of European Communities (Infant Formulae and Follow-on Formulae) Regulations, 1998 to 2000. FSAI, Dublin, Ireland.

Gaiani, C., J. Ehrhardt, J. Scher, J. Hardy, S. Desobry, and S. Banon. 2006. Surface composition of dairy powders observed by X-ray photoelectron spectroscopy and effects on their rehydration properties. Colloids Surf. B Biointerf. 49:71-78.

Herrington, T. M., and A. C. Brandfield. 1984. Physico-chemical studies on sugar glasses. Part 1: Rates of crystallization. J. Food Technol. 19:409-425.

Karmas, R., and M. Karel. 1994. The effect of glass transition on Maillard browning in food models. Pages 182-187 in Maillard Reactions in Chemistry, Food and Health. Special publication no. 151. T. P. Labuza, G. A. Reineccius, V. M. Monnier, and J. O’Brien, ed. Royal Society of Chemistry, Cambridge, UK.

Kim, M. N., M. Saltmarch, and T. P. Labuza. 1981. Non-enzymatic browning of hygroscopic whey powders in open versus sealed pouches. J. Food Proc. Preserv. 5:49-57.

Labuza, T. P., S. R. Tannenbaum, and M. Karel. 1970. Water content and stability of low-moisture and intermediate-moisture foods. Food Technol. 24:35-42.

Levine, H., and L. Slade. 1986. A polymer physicochemical approach to the study of commercial starch hydrolysis products (SHPs). Carbohyd. Polym. 6:213-244.

Lloyd, R. J., X. D. Chen, and J. B. Hargreaves. 1996. Glass transition and caking of spray-dried lactose. Int. J. Food Sci. Technol. 31:305-311.

Millqvist-Fureby, A., M. Malmsten, and B. Bergenståhl. 1999. Surface characterization of freeze-dried protein/carbohydrate mixtures. Int. J. Pharmacol. 191:103-114.

Nasirpour, A., J. Scher, and S. Desobry. 2006. Modeling of lactose crystallization and color changes in model infant foods. J. Dairy Sci. 89:2365-2373.

Özkan, N., B. Withy, and X. D. Chen. 2003. Effects of time, temperature, and pressure on the cake formation of milk powders. J. Food Eng. 58:355-361.

Rennie, P. R., X. D. Chen, C. Hargreaves, and A. R. Mackereth. 1999. A study of the cohesion of dairy powders. J. Food Eng. 39:277-284.

Saltmarch, M., and T. P. Labuza. 1980. Influence of relative humidity on the physicochemical state of lactose in spray-dried sweet whey powders. J. Food Sci. 45:1231-1236, 1242.

Thomas, M. E. C., J. Scher, and S. Desobry. 2004. Lactose/ $\beta$-lactoglobulin interaction during storage of model whey powders. J. Dairy Sci. 87:1158-1166.

Vuataz, G. 1988. Preservation of skim milk powders: Role of water activity and temperature in lactose crystallization and lysine loss. Pages 73-101 in Food Preservation by Moisture Control. C. C. Seow, ed. Elsevier Applied Science Publishers, London, UK.

Vuataz, G. 2002. The phase diagram of milk: A new tool for optimizing the drying process. Lait 82:485-500. 